\title{
Effect of gamma-sterilization and autoclaving on soil organic matter structure as studied by solid state NMR, UV and fluorescence spectroscopy
}

OnlineOpen: This article is available free online at www.blackwell-synergy.com

\author{
A. E. Berns, H. Philipp, H.-D. Narres, P. Burauel, H. Vereecken \& W. Tappe \\ Forschungszentrum Jülich GmbH, Institute of Chemistry and Dynamics of the Geosphere, Institute 4 - Agrosphere, 52425 Jülich, \\ Germany
}

\begin{abstract}
Summary
Sterilized soil is often used, for example in degradation studies, sorption experiments, microbiological tests and plant test systems, to distinguish between microbial processes and abiotic reactions. The most commonly used technique for sterilization is autoclaving of the soil. Another technique is irradiation with highlevel gamma radiation ( $\gamma$-radiation). One major drawback of sterilization procedures is the possible alteration of the structure of soil components, for example the organic matter. A change in the chemical structure of the soil organic matter can cause different reactions in the above-mentioned experiments and hence interfere with the aim of clearly distinguishing between biotic and abiotic processes. Two soils (Gleyic Cambisol and Orthic Luvisol) were sterilized by two $\gamma$-irradiation procedures (4 kGy hour ${ }^{-1}$ for 9 hours and $1.3 \mathrm{kGy}_{\text {hour }}{ }^{-1}$ for 27 hours) and repeated autoclaving at $121^{\circ} \mathrm{C}$. Gentle physical aggregate fractionation of the sterilized soils revealed a decrease in the aggregation of the soil, which was reflected in an increase of the clay fraction. Subsequent analysis of the aqueous phase revealed much more dissolved organic matter (DOM) in the $\gamma$-sterilized and autoclaved soils than in the untreated soils. Ultraviolet (UV) and fluorescence spectra of the DOM showed a decrease in the aromaticity and polycondensation of the dissolved organic carbon (DOC). ${ }^{13} \mathrm{C}$ cross-polarization/magicangle spinning nuclear magnetic resonance $\left({ }^{13} \mathrm{C}-\mathrm{CP} / \mathrm{MAS} \mathrm{NMR}\right)$ spectra of the unfractionated soils and their respective soil fractions before and after sterilization showed that the most important change occurred in the carbohydrate and $\mathrm{N}$-alkyl region, the main components of microorganisms. In general, the impact of the sterilization method was stronger for autoclaving. The $\gamma$-sterilized soils and fractions displayed both fewer and smaller changes in the soil organic matter.
\end{abstract}

\section{Introduction}

Sterilized soil is frequently used as a control to differentiate between microbial processes and abiotic reactions, for example in degradation studies of pesticides or other xenobiotics, sorption and mobility experiments, re-colonization studies, plant test systems or microbiological tests such as enzyme assays (Liebich et al., 2006). One major drawback of sterilization procedures is the possible alteration of the soil's physical and chemical structure, and hence of soil properties. Changes in the chemical structure of soil organic matter (SOM) or in the physical structure of soil aggregates can cause additional effects in the

Correspondence: A. E. Berns. E-mail: a.berns@fz-juelich.de

Received 15 February 2007; revised version accepted 18 December 2007

Re-use of this article is permitted in accordance with the Creative Commons Deed, Attribution 2.5, which does not permit commercial exploitation. above-mentioned experiments and tests, and therefore interfere with the aim of distinguishing clearly between biotic and abiotic processes. The range of sterilization methods available spans from heat sterilization, particularly autoclaving, and irradiation with high-level $\gamma$-radiation, right up to chemical techniques. Several reviews on the effects of different sterilization methods on physical, chemical and biological soil properties have been published (Liegel, 1986; Wolf \& Skipper, 1994; Trevors, 1996; McNamara et al., 2003). The most recent review (McNamara et al., 2003) deals with $\gamma$-sterilization and reviews the literature over the last 50 years. These reviews and the papers they take into account focus on the changes in the cation and anion exchange capacities and extractabilities of different elements. The essential plant nutrients and elements, which can be toxic for plants at large concentrations, were of particular interest because a major application of sterilized soils is in plant studies. This could also explain why the effects 
on soil organic matter have generally been ignored until now. Sterilization has been found to cause a general increase in the extractability of manganese, ammonium and organic nitrogen, but to have no impact on physical soil properties (Wolf \& Skipper, 1994; McNamara et al., 2003). Apart from increased levels of extractable Mn, N, P and S, elevated levels of extractable organic carbon have also been observed as a result of autoclaving (Liegel, 1986; Wolf \& Skipper, 1994). Tanaka et al. (2003) noticed minimal changes in the general physicochemical soil properties during autoclaving. The small increase in soil $\mathrm{pH}$ was attributed to an accumulation of ammonium caused by the decomposition of dead microorganisms and the loss of ammonium-oxidizing bacteria. Nègre et al. (1995) studied the effect of ethylene oxide sterilization on soil organic matter with infrared (IR) and ${ }^{13} \mathrm{C}$ cross-polarization/magicangle spinning nuclear magnetic resonance $\left({ }^{13} \mathrm{C}-\mathrm{CP} / \mathrm{MAS}\right.$ NMR). The IR and ${ }^{13} \mathrm{C}-\mathrm{NMR}$ spectra revealed hydroxyalkylation, the formation of ether bonds, and a reaction between the carboxylic groups and ethylene oxide. Our literature review revealed that although quite a number of studies have concerned themselves with soil sterilization methods and their effects on soil properties and subsequent studies (Lotrario et al., 1995; Getenga et al., 2004), no systematic analysis of the changes in the soil organic matter structure caused by sterilization of the soil has yet been performed. We therefore decided to study the effect of two common soil sterilization methods ( $\gamma$-sterilization and autoclaving) on two different types of agricultural soils. We analysed the effects on the chemical structure of the soils by ${ }^{13} \mathrm{C}-\mathrm{CP} / \mathrm{MAS}$. In order to gain further insight into the soil organic matter structure, we also studied different physical size fractions of the soils by ${ }^{13} \mathrm{C}-\mathrm{CP} / \mathrm{MAS}$ and investigated the effects on the composition of dissolved organic carbon by fluorescence and UV spectroscopy.

\section{Materials and methods}

\section{Materials}

Two soil types were used for our studies: a Gleyic Cambisol from the field site at Kaldenkirchen - Hülst $\left(51^{\circ} 18^{\prime} 40^{\prime \prime} \mathrm{N}\right.$, $\left.6^{\circ} 12^{\prime} 10^{\prime \prime} \mathrm{E}\right)$ near the Forschungszentrum Jülich, Germany (Pütz \& Klimsa, 1991) and an Orthic Luvisol derived from loess taken from the field site at Merzenhausen $\left(50^{\circ} 55^{\prime} 50^{\prime \prime} \mathrm{N}\right.$, $6^{\circ} 17^{\prime} 50^{\prime \prime} \mathrm{E}$ ), also near the Forschungszentrum Jülich, Germany (Kasteel et al., 2005). Selected soil characteristics are shown in Table 1.

Chemicals and solvents were purchased from the companies Sigma-Aldrich (Steinheim, Germany), Riedel-de Haën (Seelze, Germany), Fluka (Buchs, Switzerland), and Merck (Darmstadt, Germany) in 'pro-analysis' quality.

\section{Sterilization methods}

The two soils were sterilized by $\gamma$-irradiation and autoclaving.
Table 1 Selected soil characteristics

\begin{tabular}{lll}
\hline Soil type & \multicolumn{1}{c}{ Gleyic Cambisol } & Orthic Luvisol \\
\hline Origin & Kaldenkirchen & Merzenhausen \\
& (NRW, Germany) & (NRW, Germany) \\
$\mathrm{pH}\left(\mathrm{CaCl}_{2}\right)$ & 5.4 & 7.1 \\
Textural class & Sandy loam & Silt loam \\
$\quad \mathrm{Sand} / \%$ & 73 & 4 \\
$\mathrm{Silt} / \%$ & 23 & 79 \\
$\mathrm{Clay} / \%$ & 4 & 17 \\
Fractions & & \\
Sand-sized $/ \%$ & 94 & 79.5 \\
Silt-sized $/ \%$ & 5 & 20 \\
Clay $/ \%$ & 1 & 0.5 \\
Fe content $/ \%$ & 0.6 & 1.7 \\
$\mathrm{C}_{\text {org }}$ content $/ \%$ & 0.86 & 0.98 \\
$\mathrm{C}_{\text {org }} / \mathrm{Fe}$ & 1.4 & 0.6 \\
\hline
\end{tabular}

${ }^{\mathrm{a}}$ Isolated from the untreated soils through gentle aggregate fractionation procedure.

$\gamma$-irradiation. $\gamma$-sterilization was performed in the storage pond for spent fuel elements at the FRJ-2 research reactor of Forschungszentrum Jülich GmbH. One and a half kilograms of each soil were irradiated with spent fuel elements as a $\gamma$-source with a resultant dose of $36 \mathrm{kGy}$ ( $4 \mathrm{kGy}$ hour $^{-1}$ for 9 hours). A second set of soil samples was irradiated at a greater distance from the radiation source and for a longer exposure time in order to acquire a similar resultant dose of $35 \mathrm{kGy}$ (1.3 kGy hour ${ }^{-1}$ for 27 hours).

Autoclaving. Three portions of $0.5 \mathrm{~kg}$ of moist soil were put into three glass dishes to give soil layers of $<2 \mathrm{~cm}$ thickness. The dishes were covered with aluminium foil and sterilized in a Fedegari autoclave (Type FVS 9110E, Tecnomara, Albuzzo, Italy) for 20 minutes at $121^{\circ} \mathrm{C}$. This procedure was repeated twice with a 24-hour incubation period in a laminar flow unit at room temperature in between.

Sterility testing. Sterility was tested in subsamples of the irradiated and autoclaved soils, respectively. In each case, $5 \mathrm{~g}$ of soil were suspended in $10 \mathrm{ml}$ of Ringer solution (1/4 strength) in five replicates and the undiluted supernatants were plated onto R2A agar plates (Oxoid, Basingstoke, England), and Standard I Nutrient Agar plates (Carl Roth GmbH, Karlsruhe, Germany). Additionally, test tubes with tryptic soy broth (Merck, Darmstadt, Germany) were incubated with undiluted supernatant from the soil suspensions. The soil samples were considered to be sterile when there was a lack of growth after an incubation period of 21 days $\left(20\right.$ and $\left.37^{\circ} \mathrm{C}\right)$. The sterilized soils were stored and handled under sterile conditions in a laminar flow unit until the gentle aggregate fractionation procedure began.

\section{Aggregate fractionation}

The soils were fractionated according to the procedure described by Schnitzler et al. (2007) and Séquaris \& Lewandowski 
(2003). The fractionation method is based on sedimentation (Stokes's law) and centrifugation steps after suspension in a $1 \mathrm{~mm} \mathrm{CaCl}_{2}$ solution. Three solid fractions were isolated: 2000-20 $\mu \mathrm{m}$ (sand-sized aggregates), 20-2 $\mathrm{m}$ (silt-sized aggregates) and $2-0.05 \mu \mathrm{m}$ (clay). The aqueous phase, containing the DOC, was $<0.05 \mu \mathrm{m}$ in size. The freeze-dried solid fractions were analysed for their organic carbon and iron contents, subjected to hydrofluoric acid (HF) extraction to eliminate paramagnetic elements and reanalysed for organic carbon (OC) and Fe. The aqueous phase was analysed for its nonpurgeable organic carbon (NPOC) content and $\mathrm{pH}$.

\section{Hydrofluoric acid treatment}

The samples were treated with hydrofluoric acid mainly to remove iron. This was done with $2 \% \mathrm{HF}(\mathrm{v} / \mathrm{v})$ as described by Skjemstad et al. (1994) and Keeler \& Maciel (2003). Three grams of each dry soil or soil fraction were shaken with $30 \mathrm{ml}$ of hydrofluoric acid in closed polyethylene centrifuge tubes for about 24 hours. The samples were centrifuged for 1 hour at $3500 \mathrm{~g}$. The supernatant was discarded and the procedure repeated four times. After $\mathrm{HF}$ treatment, the samples were washed four times with $30 \mathrm{ml}$ of distilled water and then freeze-dried. Of the fractions containing little material, $0.5 \mathrm{~g}$ were treated with $5 \mathrm{ml} \mathrm{HF}$.

\section{NMR spectroscopy}

${ }^{13} \mathrm{C}$ cross-polarization/magic-angle spinning nuclear magnetic resonance $\left({ }^{13} \mathrm{C}-\mathrm{CP} / \mathrm{MAS} \mathrm{NMR}\right)$ spectra of the freeze-dried solid fractions and unfractionated soil samples were obtained on a NMR spectrometer INOVA ${ }^{\mathrm{TM}}$ Unity (Varian Inc., Palo Alto, CA) equipped with a wide-bore probe operating at $75.4 \mathrm{MHz}$ for ${ }^{13} \mathrm{C}$ (7.05 $\mathrm{T}$ magnet). The samples were placed in 6-mm diameter zirconium rotors with Teflon ${ }^{\circledR}$ bottoms and top spacers and Vespel ${ }^{\circledR}$ drive tips. The temperature was set at $25 \pm 0.1^{\circ} \mathrm{C}$ and magic angle spinning was carried out at $5000 \pm 1 \mathrm{~Hz}$. A ramped cross-polarization sequence was applied with an ascending $\mathrm{H}$-ramp of $6-\mathrm{kHz}$ ramp width. During the acquisition of the free induction decays (FIDs), a continuous wave decoupling was applied. The FIDs were collected using $4 \mathrm{k}$ data points over an acquisition time of $30 \mathrm{~ms}$. The $90^{\circ}$ pulse length, contact time and recycle delay were determined in separate experiments and were $4 \mu \mathrm{s}, 1 \mathrm{~ms}$ and $2 \mathrm{~s}$, respectively. Some spectra were repeated with a spinning rate of $7500 \pm 1 \mathrm{~Hz}$ in order to identify spinning side bands. Glycine was used as an external shift reference. Chemical shift values are given in parts per million relative to tetramethylsilane. VNMRJ software (Version 1.1 RevisionD, Varian Inc., Palo Alto, CA, USA) was used to acquire all FIDs. Spectra elaboration was conducted with MestRe-C software (Version 4.9.9.9, Mestrelab Research, Santiago de Compostela, Spain). All of the FIDs were transformed by applying an $8 \mathrm{k}$ zero filling followed by an exponential filter function with a line broadening (LB) of $50 \mathrm{~Hz}$. A second order polynomial was used with the Bernstein algorithm for baseline correction of the NMR spectra (Brown, 1995). Signal attribution was conducted by dividing the spectra into the following five regions: 185-160 p.p.m. (region V: carboxylic C), 160-110 p.p.m. (region IV: aromatic C), 110-90 p.p.m. (region III: anomeric C), 90-45 p.p.m. (region II: oxidized carbon from carbohydrates and N-alkyls), and 45-0 (region I: alkyl C) (Wilson, 1987). Spinning side bands (SSB) caused by carboxylic groups, aromatic systems and alkyl groups were accounted for, and the spectra were corrected by adding the side bands to their respective central peak and subtracting underlying side bands from the affected regions. This correction of the spectra has previously been reported as being effective in improving the assessment of the relative peak areas (Conte et al., 1997). However, it should be borne in mind that the SSB shapes may be unsymmetrical in respect of the central band (Duer, 2002).

\section{Elemental analyses}

The amount of non-purgeable organic carbon (NPOC) in the aqueous solutions was determined with a TOC analyser 5050A equipped with an autosampler ASI-5000A from Shimadzu (Kyoto, Japan). Each sample was acidified with $1 \mathrm{M} \mathrm{HCl}$, purged with $\mathrm{CO}_{2}$-free synthetic air (Spezial-X50S, Air Products, Hattingen, Germany) to eliminate volatile carbon, and then measured three times. The OC content of the solid samples was measured in triplicate with a Leco CHNS-932 analyser (LECO Corp., St Joseph, MI, USA) in the Central Division of Analytical Chemistry at Forschungszentrum Jülich GmbH. The iron analysis was performed at the Central Division of Analytical Chemistry at Forschungszentrum Jülich GmbH. To determine the Fe content of the solid samples, $50 \mathrm{mg}$ were digested with $250 \mathrm{mg}$ of lithium borate at $1000^{\circ} \mathrm{C}$ for 30 minutes. The pellet was subsequently dissolved in $50 \mathrm{ml}$ of hydrochloric acid $(5 \%)$. The acidic solution was then analysed with an inductively coupled plasma optical emission spectrometer (ICP-OES, IRIS Intrepid, Thermo Elemental Ltd., Winsford, UK). Three replicate measurements were taken for each sample.

\section{UV spectroscopy}

UV absorbance spectra of the aqueous solutions were recorded in duplicate on a Uvikon $860 \mathrm{UV} /$ Vis spectrometer (Tegimenta AG, Rotkreuz, Switzerland). The UV absorbance at $254 \mathrm{~nm}$ measured in inverse metres $\left(\mathrm{m}^{-1}\right)$ divided by the organic carbon concentration measured in milligrammes per litre $\left(\mathrm{mg} \mathrm{litre}^{-1}\right)$ is defined as the $\mathrm{SUVA}_{254}$ index (Leenheer \& Croué, 2003; Weishaar et al., 2003). Where necessary, the samples were diluted with $1 \mathrm{~mm} \mathrm{CaCl}_{2}$ to a concentration below $5 \mathrm{mg} \mathrm{C}$ litre ${ }^{-1}$.

\section{Fluorescence spectroscopy}

The fluorescence emission spectra of the aqueous samples were recorded in duplicate with a luminescence spectrometer Cary 
Eclipse (Varian, Darmstadt, Germany) by the method described by Schnitzler et al. (2007). The same dilutions were applied as for the UV measurements. The excitation wavelength was fixed at $254 \mathrm{~nm}$ and the emission wavelength ranged from 300 to $480 \mathrm{~nm}$. The bandwidths of the excitation and emission slits were set at $5 \mathrm{~nm}$ and the scan speed was $120 \mathrm{~nm}$ minutes $^{-1}$. The humification index $\left(\mathrm{HIX}_{\mathrm{EM}}\right)$ was defined as the sum of fluorescence intensity from 435 to $480 \mathrm{~nm}$ divided by the sum of intensity from 300 to $345 \mathrm{~nm}$, as described by Zsolnay (2003).

\section{Results and discussion}

\section{Aggregate-size fractions}

The soils were fractionated according to the sedimentation procedure described by Schnitzler et al. (2007) and Séquaris \& Lewandowski (2003) especially designed to preserve microaggregates as far as possible and to monitor the disaggregation of microaggregates and the release of water-dispersible colloids. The impact of the sterilization method on the weight distribution of the silt-sized aggregate and clay fractions is shown in Figure 1. Both sterilization methods lead to an increase in the clay fraction and a decrease in the silt-sized aggregate fraction in both soils. This indicates that both sterilization procedures destroy soil aggregates to some extent. However, this effect is more pronounced in the autoclaved soils than in the $\gamma$-irradiated soils. When comparing the textural composition of both soils (Table 1) and the proportions of the aggregate fractions of the unsterilized soils determined after our gentle aggregate fractionation procedure (black columns in Figure 1), a considerably stronger aggregation state was observed for the Luvisol than for the Cambisol.

For the determination of textural classes, soils are usually completely dispersed. However, the gentle aggregate fractionation procedure applied in this study explicitly avoids the destruction of small aggregates. The Luvisol, which is a silt loam with a clay content of $17 \%$ (textural class determination) yields a much smaller clay fraction $(0.5 \%)$ when the gentle aggregate fractionation procedure is applied. Furthermore, the Luvisol sand-sized aggregate fraction is about $79.5 \%$, which is dramatically larger than the measured real sand content of $4 \%$ (from the textural class determination). Therefore, the main constituents of the sand-sized aggregate fraction in the Luvisol are silt and/or clay, indicating a very strong aggregation of small soil particles in the Luvisol. In contrast, the Cambisol has a sand-sized aggregate fraction of $94 \%$ versus a sand content of $73 \%$. The aggregation of soil particles is obviously much stronger in the Luvisol as compared with the Cambisol. However, both sterilization methods only release a small part of the clay in the Luvisol, while about two-thirds of the clay content are released in the Cambisol after sterilization.

In the present study, both autoclaving and sterilization by $\gamma$-radiation altered the aggregation state of the soil. The extent of disaggregation is different for each soil and appears to depend
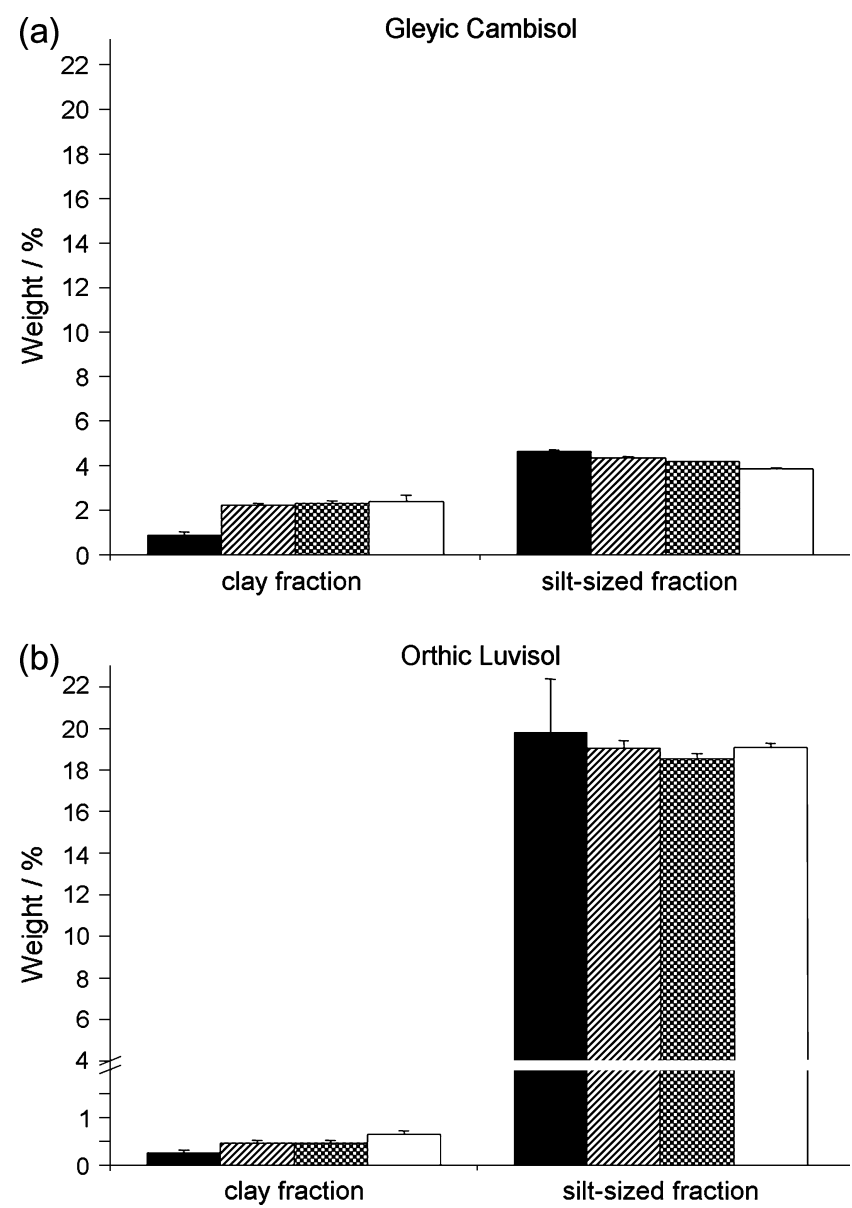

Figure 1 Weight distribution of the silt-sized aggregate and clay fractions before and after sterilization (black $=$ non-sterile; striped $=9$ hours $\gamma$-sterilized; chequered $=27$ hours $\gamma$-sterilized; white $=$ autoclaved).

on the intrinsic aggregate stability. Somewhat contradictory reports exist in the literature on the effects of sterilization methods on the soil aggregate stability. As summarized by McNamara et al. (2003), most authors found no significant changes in the surface area or particle size distribution after $\gamma$-irradiation (Griffiths \& Burns, 1968; Lensi et al., 1991). Salonius et al. (1967), however, found a decrease in clay aggregate stability after irradiation and an increase after autoclaving. Lotrario et al. (1995) found that $\gamma$-irradiation had a minimal effect on the size distribution, while autoclaving led to increased aggregation with a reduced surface area. The authors suggested that the small pores collapsed as a result of pressurization and depressurization during autoclaving. These differences are probably due to the use of different analytical methods in determining the aggregation of the soil (mechanical sieving separation versus gentle aggregate fractionation procedure). Although Griffiths \& Burns (1968) found no significant effect on soil aggregation after $\gamma$-irradiation, the authors pointed out that extracellular polysaccharides from microorganisms are effective aggregating agents but that 
a reduction in their chain length, which could be caused by the sterilization process, reduces their capacity to aggregate soil particles.

In our case, autoclaving appeared to destroy more polysaccharide structures holding the microaggregates together than $\gamma$ sterilization, and therefore more microaggregates disaggregated after autoclaving. The destruction of aggregates has an influence on the soil surface and on the accessibility of previously hidden reaction sites or potential nutrients formerly stabilized within the soil matrix. Hence, the concentration of ions and dissolved organic matter (DOM) in the liquid phase will increase. The drastic increase of DOM after sterilization is shown in Figure $4 \mathrm{a}$ and will be discussed later. The increase of different ions, and their influence on plant growth in subsequently performed plant growth studies, has already been extensively reported elsewhere (Ferriss, 1984; Liegel, 1986; Tanaka et al., 2003) and was not considered in this study.

\section{HF treatment of the samples}

The $\mathrm{C}_{\text {org }} / \mathrm{Fe}$-ratios in both soils (Table 1) were inapplicable for NMR analysis as paramagnetic soil constituents, especially $\mathrm{Fe}^{3+}$, cause a loss of signal intensity in the ${ }^{13} \mathrm{C}-\mathrm{CP} / \mathrm{MAS}$ spectra. Schnitzer (2001) stated that the $\mathrm{C}_{\text {org }} / \mathrm{Fe}$ ratio is a good indicator for obtaining reasonable ${ }^{13} \mathrm{C}$ NMR spectra and that ratios $>>1$ will give spectra of good quality, but that ratios below 1 will result in poor spectra. The extremely low $\mathrm{C}_{\text {org }} / \mathrm{Fe}$-ratios of the Luvisol soil, in particular, rendered the NMR analysis impracticable without prior treatment with $2 \% \mathrm{HF}$ in order to get rid of iron in the soil samples. Iron extraction using HF is now a routinely applied treatment (Skjemstad et al., 1994; Schmidt et al., 1997; Schnitzer, 2001; Keeler \& Maciel, 2003).

Three points must be considered when treating soil samples with hydrofluoric acid. First, paramagnetic impurities in soil samples, such as iron, may induce selective signal depression. As the efficiency of this discriminating effect depends on the distance between iron and carbon, chemically bound iron ions will induce a selective signal loss, while physical mixtures will cause a nonselective loss in signal intensity. Jancke et al. (2002) concluded from their study that the signal attenuation caused by $\mathrm{Fe}^{3+}$ in soil is mainly non-selective. Second, a problem may arise from chemical alterations of the organic matter induced by the contact with the hydrofluoric acid. Keeler \& Maciel (2003) found significant albeit undramatic changes in the organic structure due to treatment with $2 \% \mathrm{HF}$. Third, the loss of organic matter due to HF treatment must also be considered (Schmidt et al., 1997; Schmidt \& Gleixner, 2005). Depending on soil types, the latter can be significant, especially when large amounts of organic matter adhere to mineral compounds like clay or iron and aluminium oxides, which can be dissolved by hydrofluoric acid (Dai \& Johnson, 1999; Smernik et al., 2003).

In our study, HF treatment had slightly different effects on the quantity of organic matter in the two soils (Table 2). If the mass loss during HF treatment is taken into account, the non- sterile Cambisol and its fractions lost more organic carbon than the sterilized Cambisol samples. The sterilized whole soils all lost similar amounts of organic carbon, whereas in the silt-sized and clay fractions, the 9 hours $\gamma$-sterilized fractions lost less organic carbon than the other sterilized fractions. In the Luvisol samples, the whole soils lost about a third of their organic carbon. In the Luvisol silt-sized fractions, the sterilized fractions lost more organic carbon than the non-sterile fraction, whereas in the clay fractions, almost all of the organic carbon was lost. The massive loss of carbon in the Luvisol clay fractions is clearly due to the dissolution of mineral components acting as a support for potentially dissolvable organic matter. The removal of iron was similarly effective in all unfractionated Cambisol samples. In the silt-sized fractions, the loss of iron was significantly less in the autoclaved fraction, whereas in the clay fractions the range of iron loss is narrower. In the Luvisol samples, only the unfractionated non-sterile soil showed a significantly smaller loss of iron. Due to the very large mass loss in the clay fractions, the iron was almost completely removed. The impossibility of obtaining spectra from untreated Luvisol clay fractions also confirmed the close association of the organic matter with the iron oxides. Overall, the HF treatment had a more consistent effect in the Luvisol samples than in the Cambisol samples, where the loss of organic carbon and iron was less uniform.

In order to determine how selective the loss of carbon during HF treatment was or if the iron caused a selective signal depression, we recorded spectra of Cambisol and Luvisol silt-sized fractions before and after HF treatment (Figure 2). Although the spectra before HF treatment were quite difficult to evaluate, repeated evaluation showed that generally in all of the spectra after HF treatment, the relative intensities of the aliphatic, carbohydrate and $\mathrm{N}$-alkyl regions (I and II) increased at the expense of the aromatic and carboxylic regions (IV and V). The treatedto-non-treated quotients of the region II/region I ratio ranged from 1.4 to 1.7 , while the respective quotients for the regions IV and $\mathrm{V}$ ranged from 0.5 to 0.7 . The selective depression of the carbohydrate and $\mathrm{N}$-alkyl region II, in particular, has already been reported by other authors (Knicker, 2004; Schöning et al., 2005). For our study, we can conclude that HF treatment, though selective for certain NMR regions, affected all spectra in the same way.

\section{${ }^{13} \mathrm{C}-\mathrm{CP} / \mathrm{MAS}$ spectra}

In their detailed study on the quantification of solid-state ${ }^{13} \mathrm{C}$ NMR spectra, Keeler \& Maciel (2003) pointed out that the spin dynamics' parameters $\mathrm{T}_{1 \rho}^{\mathrm{H}}, \mathrm{T}_{\mathrm{CH}}$ and $\mathrm{T}_{1}^{\mathrm{H}}$ have to be the same for each peak in a given spectrum and for each sample in a set for a reasonable quantitation with $\mathrm{CP} / \mathrm{MAS}$. As we did not perform these measurements, we abstained from a quantitative evaluation of our spectra. A relative evaluation of the spectra within one set was nevertheless considered legitimate, as the samples from every set were of the same nature and, even if the relevant parameters may have differed between 
Table $2 \mathrm{C}_{\text {org }}$ - and Fe-contents of the unfractionated soils and the aggregate fractions before and after HF treatment

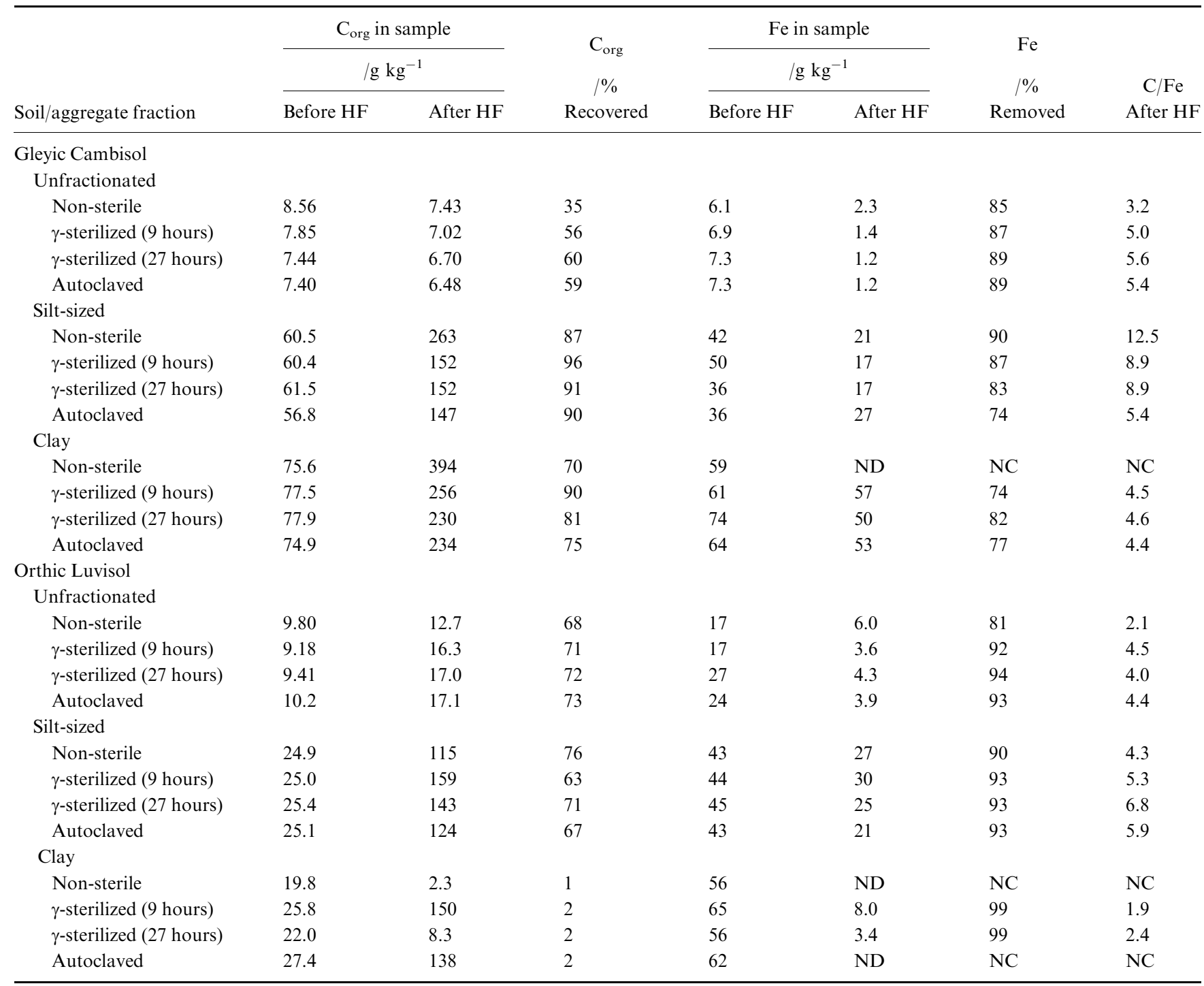

$\mathrm{NC}=$ not computable; $\mathrm{ND}=$ not determined.

peaks in one spectrum, for a given peak in a set of spectra, it was likely that the parameters remained more or less unchanged. To better visualize the differences in the spectra and to take into account the effect of the spinning side bands, the relative areas of the peaks are presented in Table 3. We strongly advise the reader, however, not to consider these values as quantitative results.

The NMR spectra of the HF-extracted Cambisol and its soil fractions are displayed in Figure 3. In the autoclaved silt-sized and clay fractions and the $\gamma$-sterilized clay fractions, the carbohydrate and $\mathrm{N}$-alkyl region II (90 to 45 p.p.m.) is significantly reduced. In the unfractionated soils, this decrease is not visible and the unfractionated autoclaved soil even displays a slight increase in this region. The aliphatic region (I) in all sterilized samples increases in the clay fractions, whereas no change can be seen in the unfractionated soils. In the silt-sized fractions, this region remains unchanged except for a decrease in the 9 hours $\gamma$-sterilized fraction accompanied by an increase in the aromatic region (IV). The above-described decrease in region II in the autoclaved silt-sized fraction is also accompanied by a slight increase in the aromatic region IV. The losses in the carbohydrate and $\mathrm{N}$-alkyl region are consistent, as these are the main constituents of microorganisms and result from their lysis. This will be discussed further in the following section on dissolved organic carbon. The increase of the aliphatic structures in the clay fractions, however, is more likely to be due to a proportionally greater loss of components from the carbohydrate region (II). Furthermore, as observed for the unfractionated soils, a spectrum of the whole soil does not necessarily show all of the changes in the structure of the organic components, as the 


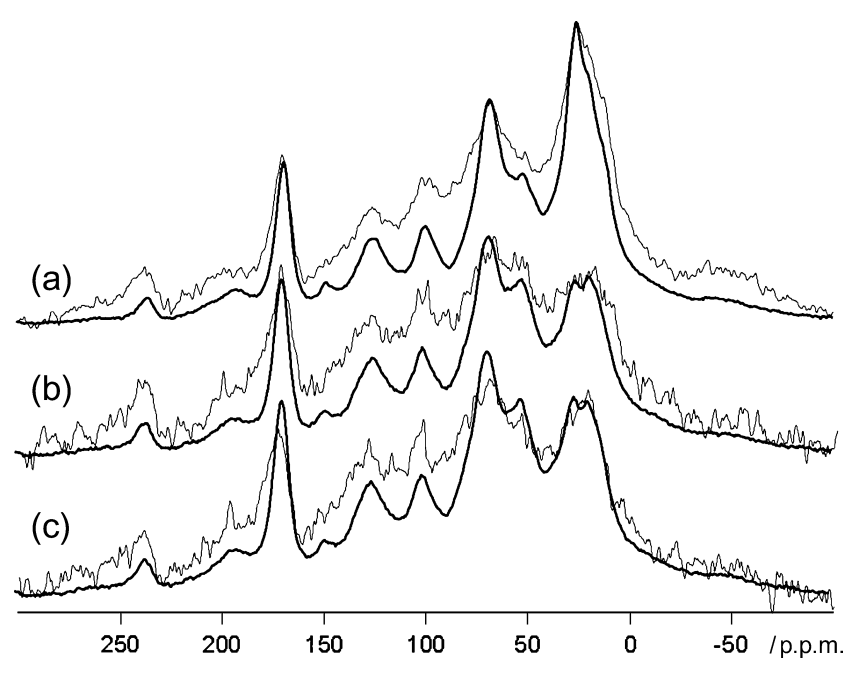

Figure $2{ }^{13} \mathrm{C}-\mathrm{CP} / \mathrm{MAS}$ spectra of silt-sized aggregate fractions before (thin line) and after (thick line) HF treatment: non-sterile Cambisol (a), non-sterile Luvisol (b) and 9 hours $\gamma$-sterilized Luvisol (c).

organic carbon is rather diluted and changes in the finest fractions can go undetected.

Figure 4 shows the NMR spectra of the HF-extracted Luvisol and its soil fractions. The autoclaved unfractionated soil displays a decrease in the carboxylic region $(\mathrm{V})$ and an increase in the di-O-alkyl region (III), whereas the $\gamma$-sterilized soils show an increase in the carbohydrate/ $\mathrm{N}$-alkyl region (II) and a slight decrease in the aliphatic region (I). In the $\gamma$-sterilized silt-sized fractions no change can be observed and the autoclaved fraction only shows a slight increase in the aromatic signal, most probably due to a disproportionate loss of carbohydrate (II) and aliphatic (I) structures. The spectrum of the non-sterile Luvisol clay fraction is difficult to evaluate because there was very little material left after $\mathrm{HF}$ treatment and the $\mathrm{S} / \mathrm{N}$ ratio was very small. The spectra of the 27 hours $\gamma$-sterilized and autoclaved clay fractions display a loss in the carbohydrate region (II), which intriguingly is not seen in the spectrum of the 9 hours $\gamma$-sterilized clay fraction. All sterilized clay fractions show a decrease in carboxylic structures (V) and an increase in aliphatic structures (I), the latter again due to a proportionally greater loss of other components. Overall, the Luvisol showed a less pronounced loss of carbohydrate and $\mathrm{N}$-alkyl structures.

In general, the strongest influence on the soil organic matter for both soils was exerted by autoclaving. Although some of the changes observed for autoclaving could also be seen for $\gamma$-sterilization, the extent of the changes was generally weaker. In both soils, the most pronounced losses occurred in the carbohydrate and $\mathrm{N}$-alkyl region (II), although they were weaker in the Luvisol, where the carbon loss seemed to be more evenly distributed among the different components. The solubilization of carbohydrates and amino acids by sterilization has already been reported by several authors (Salonius et al., 1967; Ferriss, 1984), and our documented loss in this region agrees with the literature findings.
Table 3 Relative NMR intensity distribution of the NMR spectra in Figures 3 and 4 after HF treatment

\begin{tabular}{|c|c|c|c|c|c|}
\hline \multirow[b]{2}{*}{ Soil/aggregate fraction } & \multicolumn{5}{|c|}{ NMR shift region } \\
\hline & $\begin{array}{c}\mathrm{V} \\
185-160 \\
\text { p.p.m. }\end{array}$ & $\begin{array}{c}\text { IV } \\
160-110 \\
\text { p.p.m. }\end{array}$ & $\begin{array}{c}\text { III } \\
110-90 \\
\text { p.p.m. } \\
/ \%\end{array}$ & $\begin{array}{c}\text { II } \\
90-45 \\
\text { p.p.m. }\end{array}$ & $\begin{array}{c}\text { I } \\
45-0 \\
\text { p.p.m. }\end{array}$ \\
\hline \multicolumn{6}{|l|}{ Gleyic Cambisol } \\
\hline \multicolumn{6}{|l|}{ Unfractionated } \\
\hline Non-sterile & 9 & 26 & 7 & 23 & 36 \\
\hline$\gamma$-sterilized (9 hours) & 8 & 27 & 7 & 22 & 36 \\
\hline$\gamma$-sterilized (27 hours) & 9 & 24 & 8 & 23 & 36 \\
\hline Autoclaved & 8 & 25 & 7 & 26 & 35 \\
\hline \multicolumn{6}{|l|}{ Silt-sized } \\
\hline Non-sterile & 12 & 19 & 5 & 21 & 44 \\
\hline$\gamma$-sterilized (9 hours) & 12 & 23 & 5 & 20 & 39 \\
\hline$\gamma$-sterilized (27 hours) & 10 & 20 & 5 & 20 & 44 \\
\hline Autoclaved & 10 & 23 & 5 & 16 & 45 \\
\hline \multicolumn{6}{|l|}{ Clay } \\
\hline Non-sterile & 12 & 18 & 6 & 23 & 42 \\
\hline$\gamma$-sterilized (9 hours) & 15 & 18 & 5 & 15 & 47 \\
\hline$\gamma$-sterilized (27 hours) & 14 & 19 & 6 & 17 & 44 \\
\hline Autoclaved & 13 & 20 & 5 & 13 & 49 \\
\hline \multicolumn{6}{|l|}{ Orthic Luvisol } \\
\hline \multicolumn{6}{|l|}{ Unfractionated } \\
\hline Non-sterile & 15 & 33 & 4 & 21 & 27 \\
\hline$\gamma$-sterilized (9 hours) & 15 & 31 & 4 & 24 & 26 \\
\hline$\gamma$-sterilized (27 hours) & 15 & 33 & 4 & 24 & 24 \\
\hline Autoclaved & 9 & 34 & 7 & 22 & 28 \\
\hline \multicolumn{6}{|l|}{ Silt-sized } \\
\hline Non-sterile & 14 & 21 & 6 & 25 & 34 \\
\hline$\gamma$-sterilized (9 hours) & 14 & 22 & 6 & 24 & 35 \\
\hline$\gamma$-sterilized (27 hours) & 14 & 22 & 6 & 24 & 34 \\
\hline Autoclaved & 15 & 26 & 5 & 22 & 32 \\
\hline \multicolumn{6}{|l|}{ Clay } \\
\hline Non-sterile & 20 & 22 & 2 & 21 & 35 \\
\hline$\gamma$-sterilized (9 hours) & 15 & 17 & 4 & 21 & 43 \\
\hline$\gamma$-sterilized (27 hours) & 17 & 20 & 4 & 17 & 42 \\
\hline Autoclaved & 17 & 23 & 3 & 15 & 42 \\
\hline
\end{tabular}

\section{Dissolved organic carbon}

The visible increase of organic carbon in the aqueous phase, and later on the changes induced by sterilization in the solid fractions, both justified a closer inspection of this fraction. Figure $5 \mathrm{a}$ shows the impact of the sterilization method on the non-purgeable organic carbon (NPOC), analysed in the aqueous phase of both soils after fractionation. This figure displays the dissolved organic carbon as a fraction of the total organic carbon. The general effect on NPOC release is similar for both soils and autoclaving had the strongest impact by far on the organic carbon release. Autoclaving produced a 29 -fold rise in the Cambisol (3.5 mg litre ${ }^{-1}$ non-sterile, $100.9 \mathrm{mg} \mathrm{litre}^{-1}$ autoclaved), approximately five times more than $\gamma$-sterilization, and a 37 -fold increase in the Luvisol $\left(2.3 \mathrm{mg} \mathrm{litre}{ }^{-1}\right.$ non-sterile, 

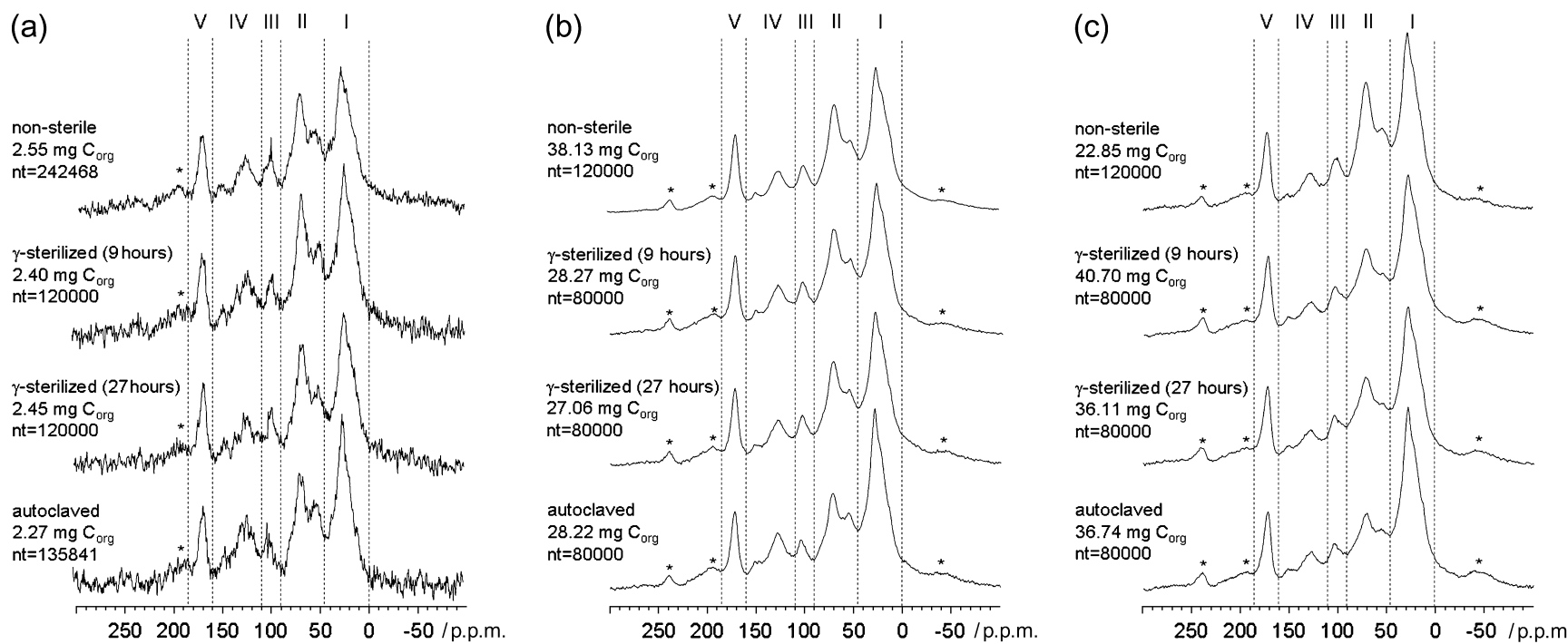

Figure $3{ }^{13} \mathrm{C}-\mathrm{CP} / \mathrm{MAS}$ spectra of the unfractionated Gleyic Cambisol (a), the silt-sized Gleyic Cambisol aggregate fraction (b) and the Gleyic Cambisol clay fraction (c) after HF treatment. For every spectrum, the amount of organic carbon in the rotor and the acquired number of transients (nt) are given. The spectra are graphically normalized to the aliphatic peak $(*=$ spinning side band).

$85.4 \mathrm{mg}$ litre ${ }^{-1}$ autoclaved), which is roughly twice the effect that $\gamma$-sterilization had on carbon release. While both $\gamma$-sterilization methods released about $2 \%$ of the total organic carbon in the Cambisol, approximately $3 \%$ of the soil organic carbon in the Luvisol was found in the DOM phase. Autoclaving solubilized $11 \%$ of the soil organic carbon in the Cambisol and 7\% in the Luvisol. This smaller percentage of soluble organic carbon after autoclaving in the Luvisol is consistent with the stronger aggregation state of the Luvisol described in the aggregate-size fractions section (Table 1). If we take into account that the increase in the amount of the clay fraction is much greater from non-sterile to the $\gamma$-sterilized than from the $\gamma$-sterilized to the autoclaved soils, autoclaving would appear to release not only the organic carbon which is physically trapped between the particles, but also to detach organic carbon from particle surfaces. The drastic increase in soluble organic carbon (though still at an overall low level) after $\gamma$-irradiation and autoclaving has already been reported (Warcup, 1957; Rotini et al., (a)

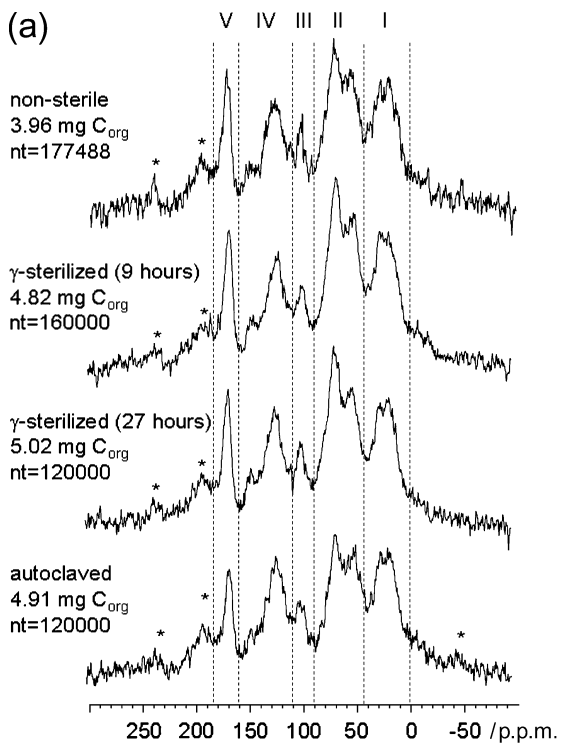

(b)

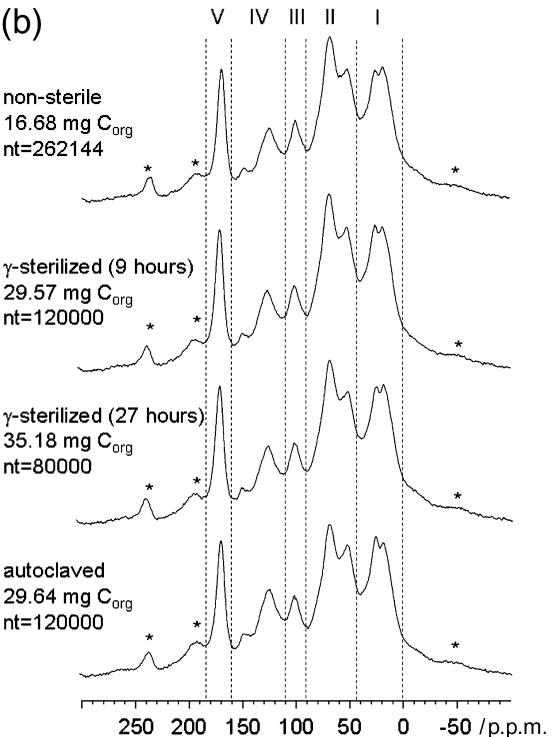

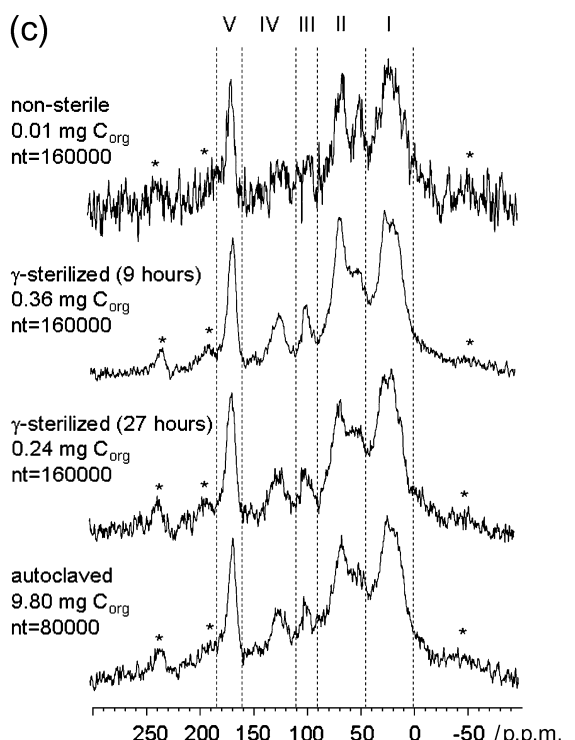

Figure $4{ }^{13} \mathrm{C}-\mathrm{CP} / \mathrm{MAS}$-spectra of the unfractionated Orthic Luvisol (a), the silt-sized Orthic Luvisol aggregate fraction (b) and the Orthic Luvisol clay fraction (c) after HF treatment. For every spectrum, the amount of organic carbon in the rotor and the acquired number of transients (nt) are given. The spectra are graphically normalized to the aliphatic peak $(*=$ spinning side band). 

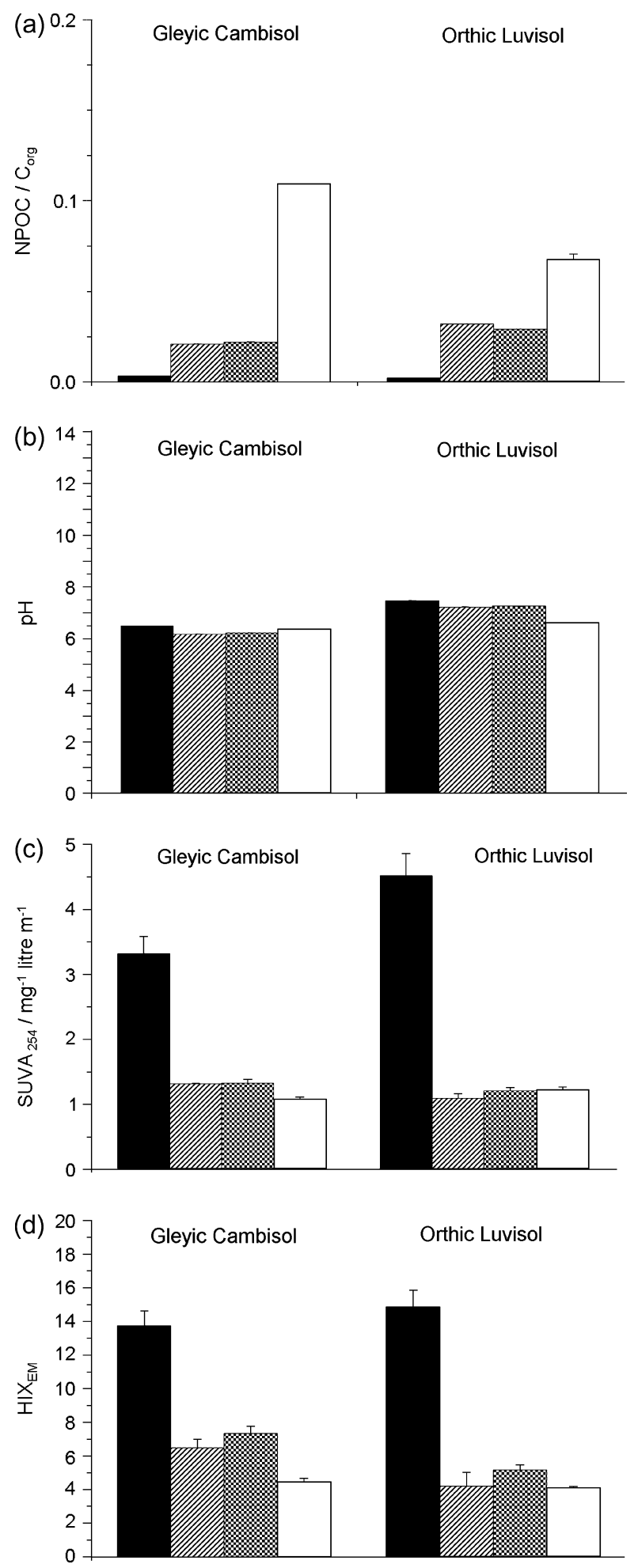

Figure 5 Ratio of non-purgeable organic carbon (NPOC) to organic carbon in the soil (a), $\mathrm{pH}$ (error bars are too small to be discernible) (b), SUVA $_{254}$ index (c) and HIX $\mathrm{EM}_{\mathrm{EM}}$ index (d) of the aqueous phases before and after sterilization (black $=$ non-sterile; striped $=9$ hours $\gamma$-sterilized; chequered $=27$ hours $\gamma$-sterilized; white $=$ autoclaved).
1963), and the stronger increase after autoclaving compared with $\gamma$-sterilization has also already been observed (Salonius et al., 1967; Powlson \& Jenkinson, 1976).

These results are generally consistent with the impact of both sterilization methods on soil aggregates (disaggregation of soil particles) as presented and discussed earlier in this paper (Aggregate-size fractions section). Despite the drastic increase in NPOC following sterilization, especially after autoclaving, our data do not allow the origin of the dissolved carbon to be traced to a particular soil fraction. The theoretical decrease of $\mathrm{C}_{\text {org }}$ in any of the soil fractions resulting in the increase of NPOC in solution cannot be resolved analytically as the amounts released are too small to be detected within the measurement errors of the $\mathrm{C}_{\text {org }}$ analysis in the solid fractions, especially as it is likely that all fractions contribute to a certain extent to the organic carbon release. However, we can safely assume that a substantial fraction of the NPOC released from soil during $\gamma$-irradiation and autoclaving is due to the lysis of microorganisms. Furthermore, cell damage and further destruction of cell material seems to be more pronounced in autoclaved soil.

Results from trials for the extraction and amplification of bacterial DNA from $\gamma$-sterilized and autoclaved Luvisol soil (data not shown) supported this hypothesis. Polymerase chain reaction (PCR) amplification using a universal bacterial primer pair yielded no product from autoclaved soil, while from $\gamma$-sterilized soil minor amounts of PCR products were obtained, although no cultivable bacteria were detected (Materials and methods section). From this, we can conclude that with respect to microorganisms and macromolecules, autoclaving is much more destructive. Lensi et al. (1991) already hypothesized that the increase in soluble organic carbon after $\gamma$-irradiation was probably due to the lysis of cells and the degradation of soil organic matter. Figure $5 \mathrm{~b}$ shows that the $\mathrm{pH}$ of the aqueous phase remains nearly unchanged in the Cambisol and decreases slightly in the Luvisol. This decrease could be due to the release of organic acids from the soil organic matter, which is also supported by the spectrum of the autoclaved soil (Figure 4a and Table 3), where a decrease of the carboxylic peak can be observed. Skipper \& Westermann (1973) also attributed the lowering of the soil $\mathrm{pH}$ after autoclaving to the release of organic acids from the soil organic matter. Figure $5 \mathrm{c}$ displays the $\mathrm{SUVA}_{254}$ indices of the aqueous phases. This index is an 'average' absorptivity and is used as an indicator for the aromaticity of the DOC (Weishaar et al., 2003; Schnitzler et al., 2007). The aromaticity of the aqueous phases decreases for each sterilization method. This is due to dilution as a result of the general increase in carbon concentration.

As seen from the NMR spectra, carbohydrate and N-alkyl structures are the major components lost from the solid organic carbon. Figure $5 \mathrm{~d}$ shows the $\mathrm{HIX}_{\mathrm{EM}}$ indices of the aqueous phases. The extent of polycondensation of the dissolved carbon can be determined with fluorescence spectroscopy by quantifying the red-shifting of fluorescence emission (Zsolnay, 
2003). As already found with NPOC measurement and the SUVA index, sterilization significantly increases the content of organic carbon in the aqueous phase, resulting in a dilution and thus a decrease in aromaticity. The HIX $\mathrm{EM}_{\mathrm{E}}$ indices also decrease, showing that the degree of polycondensation of the aromatic fraction is less after sterilization. The sterilization process hence seems to release uncondensed basic aromatic components, which cause a reduction in the HIX $\mathrm{EM}_{\mathrm{M}}$ index.

\section{Conclusions}

Both $\gamma$-sterilization and autoclaving were effective in sterilizing soil and no living microorganisms could be detected during sterility testing. However, some changes in the soils could be documented and these must be considered when using sterilized soils. One such change is the alteration of the aggregation state of soil aggregates leading to a greater soil surface area. Hence, if autoclaved or $\gamma$-sterilized soil is used as an abiotic control in degradation/sorption studies, the increase in soil surface area may have an additional influence on the reference as well. Both methods caused significant though not dramatic changes in the soil organic matter structure, and mainly led to changes in the carbohydrate and $\mathrm{N}$-alkyl regions of the ${ }^{13} \mathrm{C}-\mathrm{CP} / \mathrm{MAS}$ spectra due to the lysis of microorganisms and subsequent loss of microbial carbon to the aqueous phase. We have shown that HF treatment caused an increase in this region and hence we can exclude this reduction as an artefact caused by the demineralization procedure. The NMR spectra of the autoclaved soils indicate additionally the loss of other carbon structures.

This hypothesis needs to be verified by further investigation into the liquid phase by liquid state NMR or Fourier transform ion cyclotron resonance mass spectroscopy (FT/ICR-MS). Our analysis revealed a drastic increase in NPOC in the aqueous phase, which might be crucial if, for example, degradation experiments with defined microbial communities in sterilized soils are to be conducted. This NPOC is suspected to consist largely of readily biodegradable carbon and could therefore serve as an additional carbon source for the microorganisms as compared with the native soil. Furthermore, the increase in NPOC was accompanied by a decrease in aromaticity and polycondensation due to dilution of the aromatic components by the release of carbohydrates, $\mathrm{N}$-alkyl structures and uncondensed aromatics. The choice of sterilization method strongly depends on the type of study or research questions being asked. If an abiotic reference without amplifiable DNA is needed, autoclaved soil is more appropriate. For plant growth, degradation or sorption experiments, however, $\gamma$-sterilized soils are better suited as control soils, because they are physically and chemically less altered by the process of sterilization. Furthermore, it has to be taken into account that changes in the soil organic matter structure cannot be generalized for different soils, except for the general loss of carbohydrates and $\mathrm{N}$-alkyl structures due to the lysis of microorganisms.

\section{Acknowledgements}

Many thanks to Dr Jean-Marie Séquaris for helpful discussions concerning the UV and fluorescence data. The authors also gratefully acknowledge the technical assistance of DI Manfred Thomé (ZFR, Forschungszentrum Jülich GmbH), DI Manfred Michulitz (ZCH, Forschungszentrum Jülich $\mathrm{GmbH})$, Dr Alexander Graf, Anita Steffen, Sirgit Kummer, Vanessa Faure-Geors and Sascha Sokolowsky.

\section{References}

Brown, D.E. 1995. Fully automated base-line correction of 1D and 2D NMR-spectra using Bernstein polynomials. Journal of Magnetic Resonance Series A, 114, 268-270.

Conte, P., Piccolo, A., van Lagen, B., Buurman, P. \& de Jager, P.A. 1997. Quantitative aspects of solid-state 13C-NMR spectra of humic substances from soils of volcanic systems. Geoderma, $\mathbf{8 0}, 327-338$.

Dai, K.H. \& Johnson, C.E. 1999. Applicability of solid-state C-13 CP/MAS NMR analysis in spodosols: chemical removal of magnetic materials. Geoderma, 93, 289-310.

Duer, M.J. (ed.) 2002. Solid-State NMR Spectroscopy. Principles and Applications. Blackwell Science Ltd, Oxford, UK.

Ferriss, R.S. 1984. Effects of microwave-oven treatment on microorganisms in soil. Phytopathology, 74, 121-126.

Getenga, Z.M., Dorfler, U., Reiner, S. \& Sabine, K. 2004. Determination of a suitable sterilization method for soil in isoproturon biodegradation studies. Bulletin of Environmental Contamination and Toxicology, 72, 415-421.

Griffiths, E. \& Burns, R.G. 1968. Effects of gamma irradiation on soil aggregate stability. Plant and Soil, 28, 169-172.

Jancke, H., Beetz, S. \& Bechmann, W. 2002. Non-selective signal loss in the C-13 CPMAS NMR spectra of soil organic matter. Investigations of particle size fractions. Journal of Environmental Monitoring, 4, 313-317.

Kasteel, R., Burkhardt, M., Giesa, S. \& Vereecken, H. 2005. Characterization of field tracer transport using high-resolution images. Vadose Zone Journal, 4, 101-111.

Keeler, C. \& Maciel, G.E. 2003. Quantitation in the solid-state C-13 NMR analysis of soil and organic soil fractions. Analytical Chemistry, 75, 2421-2432.

Knicker, H. 2004. Solid-state NMR investigations of organic matter conversions during solid-waste processing. In: Resource Recovery and Reuse in Organic Solid Waste Management (ed. W. Bidlingmaier), pp. 171-192. IWA Publishing, London, UK.

Leenheer, J.A. \& Croué, J.P. 2003. Characterizing aquatic dissolved organic matter. Environmental Science \& Technology, 37, 18a-26a.

Lensi, R., Lescure, C., Steinberg, C., Savoie, J.M. \& Faurie, G. 1991. Dynamics of residual enzyme-activities, denitrification potential, and physicochemical properties in a gamma-sterilized soil. Soil Biology \& Biochemistry, 23, 367-373.

Liebich, J., Vereecken, H. \& Burauel, P. 2006. Microbial community changes during humification of C-14-labelled maize straw in heattreated and native Orthic Luvisol. European Journal of Soil Science, 57, 446-455.

Liegel, L.H. 1986. Effects of sterilization procedures on the biological, chemical, and physical properties of soils - a review. Turrialba, 36, 11-19. 
Lotrario, J.B., Stuart, B.J., Lam, T., Arands, R.R., O'Connor, O.A. \& Kosson, D.S. 1995. Effects of sterilization methods on the physical characteristics of soil - implications for sorption isotherm analyses. Bulletin of Environmental Contamination and Toxicology, 54, 668-675.

McNamara, N.P., Black, H.I.J., Beresford, N.A. \& Parekh, N.R. 2003. Effects of acute gamma irradiation on chemical, physical and biological properties of soils. Applied Soil Ecology, 24, 117-132.

Nègre, M., Gennari, M., Crecchio, C. \& Ruggiero, P. 1995. Effect of ethylene-oxide sterilization on soil organic matter, spectroscopic analysis, and adsorption of acifluorfen. Soil Science, 159, 199-206.

Powlson, D.S. \& Jenkinson, D.S. 1976. Effects of biocidal treatments on metabolism in soil. 2. gamma-irradiation, autoclaving, air-drying and fumigation. Soil Biology \& Biochemistry, 8, 179-188.

Pütz, T. \& Klimsa, K. 1991. Profilbeschreibung und Analysenergebnisse des Standortes Kaldenkirchen - Hülst. Interner Bericht IRA 6/91, Forschungszentrum Jülich GmbH, Jülich, Germany.

Rotini, O.T., Lotti, G. \& Baldacci, P.V. 1963. Studies on the changes occurring in soils and clays heated at $50^{\circ} \mathrm{C}$ and $100^{\circ} \mathrm{C}$. Agrochimica, 7, 289-295.

Salonius, P.O., Robinson, J.B. \& Chase, F.E. 1967. A comparison of autoclaved and gamma-irradiated soils as media for microbial colonization experiments. Plant and Soil, 27, 239-248.

Schmidt, M.W.I. \& Gleixner, G. 2005. Carbon and nitrogen isotope composition of bulk soils, particle-size fractions and organic material after treatment with hydrofluoric acid. European Journal of Soil Science, 56, 407-416.

Schmidt, M.W.I., Knicker, H., Hatcher, P.G. \& Kögel-Knabner, I. 1997. Improvement of $13 \mathrm{C}$ and $15 \mathrm{~N}$ CPMAS NMR spectra of bulk soils, particle size fractions and organic material by treatment with $10 \%$ hydrofluoric acid. European Journal of Soil Science, 48, 319-328.

Schnitzer, M. 2001. The in situ analysis of organic matter in soils. Canadian Journal of Soil Science, 81, 249-254.

Schnitzler, F., Lavorenti, A., Berns, A.E., Drewes, N., Vereecken, H. \& Burauel, P. 2007. The influence of maize residues on the mobility and binding of benazolin: investigating physically extracted soil fractions. Environmental Pollution, 147, 4-13.
Schöning, I., Knicker, H. \& Kögel-Knabner, I. 2005. Intimate association between $\mathrm{O} / \mathrm{N}$-alkyl carbon and iron oxides in clay fractions of forest soils. Organic Geochemistry, 36, 1378-1390.

Séquaris, J.M. \& Lewandowski, H. 2003. Physicochemical characterization of potential colloids from agricultural topsoils. Colloids and Surfaces A - Physicochemical and Engineering Aspects, 217, 93-99.

Skipper, H.D. \& Westermann, D.T. 1973. Comparative effects of propylene oxide, sodium azide, and autoclaving on selected soil properties. Soil Biology \& Biochemistry, 5, 409-414.

Skjemstad, J.O., Clarke, P., Taylor, J.A., Oades, J.M. \& Newman, R.H. 1994. The removal of magnetic materials from surface soils a solid-state 13C CP/MAS NMR study. Australian Journal of Soil Research, 32, 1215-1229.

Smernik, R.J., Oliver, I.W. \& Merrington, G. 2003. Characterization of sewage sludge organic matter using solid-state carbon-13 nuclear magnetic resonance spectroscopy. Journal of Environmental Quality, 32, 1516-1522.

Tanaka, S., Kobayashi, T., Iwasaki, K., Yamane, S., Maeda, K. \& Sakurai, K. 2003. Properties and metabolic diversity of microbial communities in soils treated with steam sterilization compared with methyl bromide and chloropicrin fumigations. Soil Science and Plant Nutrition, 49, 603-610.

Trevors, J.T. 1996. Sterilization and inhibition of microbial activity in soil. Journal of Microbiological Methods, 26, 53-59.

Warcup, J.H. 1957. Chemical and biological aspects of soil sterilization. Soils and Fertilizers, 20, 1-5.

Weishaar, J.L., Aiken, G.R., Bergamaschi, B.A., Fram, M.S., Fujii, R. \& Mopper, K. 2003. Evaluation of specific ultraviolet absorbance as an indicator of the chemical composition and reactivity of dissolved organic carbon. Environmental Science \& Technology, 37, 4702-4708.

Wilson, M.A. 1987. NMR Techniques and Applications in Geochemistry and Soil Chemistry. Pergamon Press, London, UK.

Wolf, D.C. \& Skipper, H.D. 1994. Soil sterilization. In: Methods of Soil Analysis. Part 2: Microbiological and Biochemical Properties (eds R.W. Weaver, S. Angle, P. Bottomley, D. Bezdicek, S. Smith, A. Tabatabai \& A. Wollum), pp. 41-51. Soil Science Society of America, Inc., Madison, WI.

Zsolnay, A. 2003. Dissolved organic matter: artefacts, definitions, and functions. Geoderma, 113, 187-209. 